\title{
Coronary remodeling and stiffness in older hypertensive patients: an MR imaging study
}

\author{
Kai Lin ${ }^{1 *}$, Donald M Lloyd-Jones ${ }^{1}$, Ying Liu' ${ }^{1}$ Xiaoming Bi ${ }^{2}$, Debiao $\mathrm{Li}^{1}$, James Carr ${ }^{1}$ \\ From 15th Annual SCMR Scientific Sessions \\ Orlando, FL, USA. 2-5 February 2012
}

\section{Summary}

There are interrelations among coronary stiffness, wall thickening and remodeling pattern in older hypertensive patients. MR techniques are able to provide both the morphology and the biomechanic information of the coronary wall in a single scan.

\section{Background}

Coronary artery remodeling is an indicator of coronary artery disease. Morphological and biomechanical changes accompany with coronary wall remodeling. Such changes can be noninvasively detected using MR imaging and may be used to predict cardiovascular events. The aim of this study is to assess interrelations among various imaging markers of the coronary remodeling in older hypertensive patients.

\section{Methods}

This study was approved by the institutional review board. Two-dimensional black-blood coronary wall MR imaging and three-dimensional whole-heart coronary MR angiography (imaging data acquired in both systole and in diastole) were performed on 65 asymptomatic hypertensive patients (73.4 years \pm 5.5 ). Coronary vessel area, wall area, lumen area, wall thickness were measured. The percent of the coronary wall occupying the vessel area (PWOV) (defined as [Vessel wall area / Vessel area $\mathrm{x} 100 \%]$ ) and coronary distensibility index (CDI) (defined as [(Lumen systolic - Lumen diastolic) / (Lumen diastolic x Pulse pressure)] x 1000) were calculated. Transverse coronary segments were assigned to two groups using mean PWOV as an ad hoc cutoff point. Coronary indices were compared between the two groups.

Radiology, Northwestern University, Chicago, IL, USA

Full list of author information is available at the end of the article

\section{Results}

Totally 259 coronary segments were eligible for analysis (mean PWOV 74.5\%). The CDI $(5.30 \pm 2.60 \mathrm{mmHg}-1)$ was significantly correlated with mean wall thickness $(1.43 \pm 0.26 \mathrm{~mm}, \mathrm{r}=0.541)$, max wall thickness $(1.92 \pm$ $0.33 \mathrm{~mm}, \mathrm{r}=0.503)$. The PWOV was significantly correlated with mean wall thickness $(r=0.647)$, max wall thickness $(\mathrm{r}=0.603)$ and lumen area $(6.57 \pm 3.44 \mathrm{~mm} 2$, $r=0.796$ ). One hundred and forty segments (group 1 ) had PWOVs higher than $74.5 \%$, while 119 segments (group 2) had PWOV lower than $74.5 \%$. Segments in group2 had a significantly lower mean $(1.29 \pm 0.22 \mathrm{~mm}$ vs. $1.54 \pm 0.23 \mathrm{~mm}, \mathrm{P}<0.001)$ and max wall thickness $(1.78 \pm 0.30 \mathrm{~mm}$ vs. $2.05 \pm 0.31 \mathrm{~mm}, \mathrm{P}<0.001)$, a larger vessel area $(27.43 \pm 8.39 \mathrm{~mm} 2$ vs. $23.05 \pm 6.35 \mathrm{~mm} 2, \mathrm{P}<$ $0.001)$, a larger lumen area $(9.04 \pm 3.34 \mathrm{~mm} 2$ vs. $4.46 \pm$ $1.68 \mathrm{~mm} 2, \mathrm{P}<0.001)$ and a higher CDI $(5.89 \pm 2.65$ mmHg-1 vs. $4.79 \pm 2.46 \mathrm{mmHg}-1, \mathrm{P}=0.001)$ compared with those of segments in group 1 . For the 10 randomly chosen cases, good intra-observer $(r=0.866$ for CDI and $\mathrm{r}=0.911$ for wall thickness) and inter-observer agreement $(r=0.812$ for CDI and $r=0.898$ for wall thickness) was found on 43 coronary segments. The scan-rescan test showed low variation between coronary measurements in 38 coronary segments from the 10 randomly chosen cases $(r=0.751$ for CDI and $r=0.816$ for wall thickness).

A set of images for coronary segments with different PWOV from a single patient is shown in Figure 1.

\section{Conclusions}

Aterial stiffness is correlated with wall thickness of the remodeled coronary artery in older hypertensive patients. Reflecting relaions between wall thickening and lumen area variation, PWOV has the potential to become a quantitative index of coronary remodeling

(c) 2012 Lin et al; licensee BioMed Central Ltd. This is an open access article distributed under the terms of the Creative Commons 


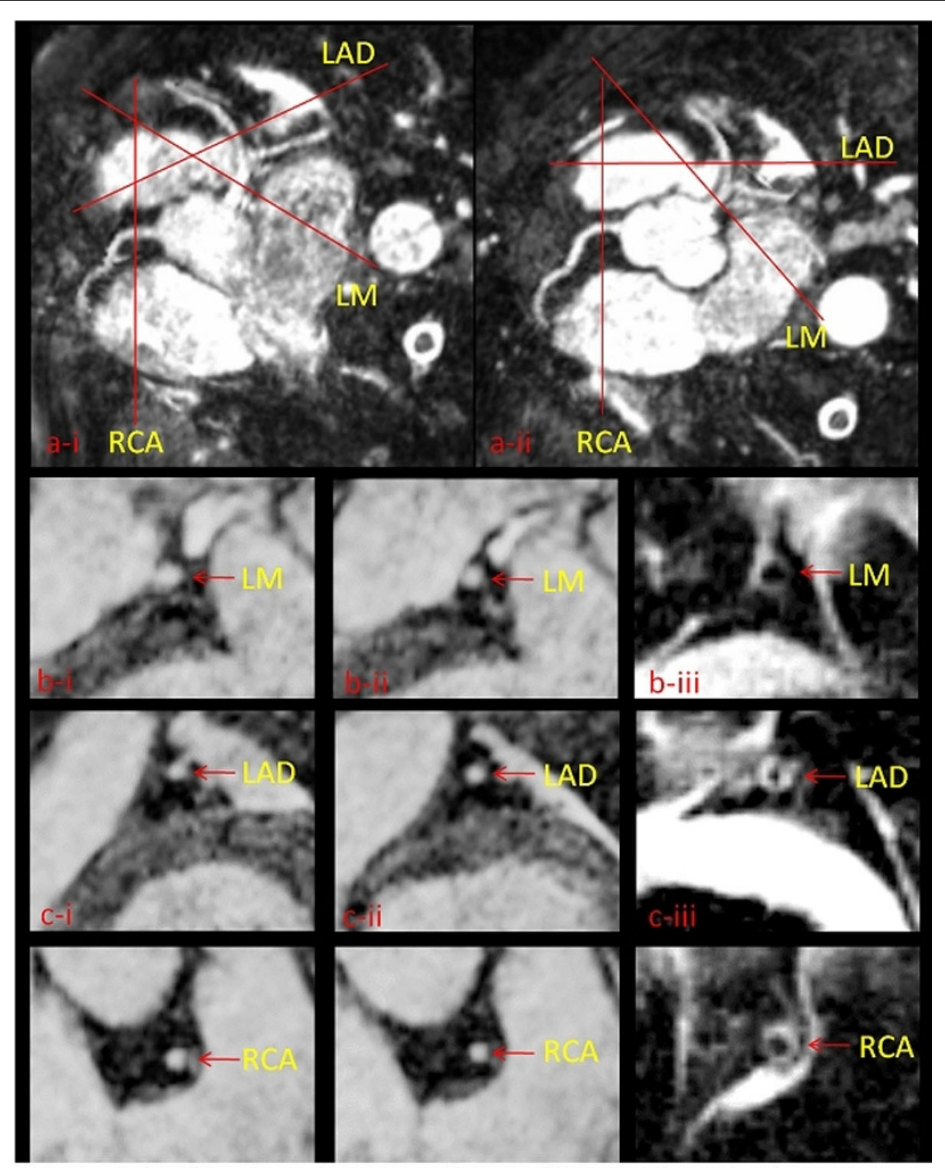

Figure $1 \mathrm{~A}$ female patient with 10-year history of hypertension. Blood pressure is $145 / 90 \mathrm{mmHg}$. The body weight is $61 \mathrm{Kg}$. a-i Coronary MR angiography (MPR) in systole, orientations of cross-sectional images on coronary branches are shown

a-ii Coronary MR angiography (MPR) in diastole, orientations of cross-sectional images on coronary branches are shown

b-i Cross-sectional view of LM in systole. The vessel area is $17.25 \mathrm{~mm} 2$. b-ii Cross-sectional view of LM in diastole. The vessel area is $9.78 \mathrm{~mm} 2$. $\mathrm{CDI}=13.89 \mathrm{mmHg}-1$

b-iii Black-blood coronary wall image at the same position of LM. Mean wall thickness $1.45 \mathrm{~mm}$. PWOV is $59.8 \%$. This segment is considered to have positive or intermediate remodeling.

c-i Cross-sectional view of LAD in systole. The vessel area is $3.76 \mathrm{~mm} 2$. c-ii Cross-sectional view of LAD in diastole. The vessel area is $3.53 \mathrm{~mm}$. $\mathrm{CDI}=1.18 \mathrm{mmHg}-1$

c-iii Black-blood coronary wall image at the same position of LAD. Mean wall thickness $2.82 \mathrm{~mm}$. PWOV is $88.4 \%$. This segment is considered to have negative remodeling.

d-i Cross-sectional view of RCA in systole. The vessel area is $8.34 \mathrm{~mm}$. $\mathrm{d}$-ii Cross-sectional view of RCA in diastole. The vessel area is $6.81 \mathrm{~mm} 2$. $\mathrm{CDI}=4.08 \mathrm{mmHg}-1$

d-iii Black-blood coronary wall image at the same position of RCA. Mean wall thickness $2.1 \mathrm{~mm}$. PWOV is $75.2 \%$. This segment is considered to have negative remodeling.

Figure $1 \mathrm{~A}$ female patient with 10-year history of hypertension.

patterns (such as positive or negative remodeling) in imaging studies.

\section{Funding}

National Institute of Health (R01HL089695)

American Heart Association (10CRP3050051) 
Table 1 Basic information of participants in present study

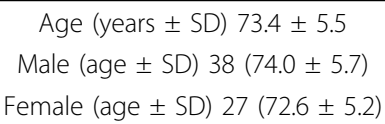

Heart rate (beats/minute \pm SD) $61 \pm 7.1$

$$
\begin{gathered}
\text { Diabetes (\%) } 17 \text { (26.2) } \\
\text { SBP }(\mathrm{mmHg}) 140.0 \pm 17.3 \\
\text { DBP }(\mathrm{mmHg}) 85.2 \pm 13.8 \\
\text { PP (mmHg) } 54.7 \pm 8.6
\end{gathered}
$$

BP under control (\%) 59 (90.7) Page 22 of 33 Prudential

\section{Author details}

${ }^{1}$ Radiology, Northwestern University, Chicago, IL, USA. ${ }^{2}$ Siemens Healthcare, Chicago, IL, USA.

Published: 1 February 2012

doi:10.1186/1532-429X-14-S1-P171

Cite this article as: Lin et al:: Coronary remodeling and stiffness in older hypertensive patients: an MR imaging study. Journal of Cardiovascular Magnetic Resonance 2012 14(Suppl 1):P171.

Submit your next manuscript to BioMed Central and take full advantage of:

- Convenient online submission

- Thorough peer review

- No space constraints or color figure charges

- Immediate publication on acceptance

- Inclusion in PubMed, CAS, Scopus and Google Scholar

- Research which is freely available for redistribution

Submit your manuscript at www.biomedcentral.com/submit
C Biomed Central 